\title{
Como os livros didáticos de alfabetização contemplam os diferentes percursos de aprendizagem?
}

\section{Maísa Alves Silva Ana Lúcia Horta Nogueira}

RESUMO: O presente artigo propõe discutir o modo como alguns livros didáticos de alfabetização levam em conta os diferentes ritmos de aprendizagem e as diferenças individuais dos alunos no processo de ensino, favorecendo situações de sucesso ou fracasso escolar. Por meio da análise de orientações ao professor e de enunciados de atividades ao aluno de seis livros didáticos, de referenciais acerca do sucesso e fracasso escolar (SAWAYA, 2012; PROENÇA, 2002; CASTRO; PIOTTO, 2007) e da Teoria Histórico Cultural (VIGOTSKI, 1995, 2007, 2010), discute a importância de que a heterogeneidade das classes escolares seja considerada, entendendo-as enquanto fonte de desenvolvimento (VIGOTSKI, 2010). As investigações mostraram a importância de levar em conta os ajustes das atividades didáticas feitos pelo professor, de modo a melhor atender os diferentes percursos de aprendizagem dos alunos, criando situações de inclusão e sucesso escolar.

PALAVRAS-CHAVE: livros didáticos de alfabetização; diferenças individuais; fonte de desenvolvimento (Vigotski).

ABSTRACT: This paper discusses how some literacy textbooks take into account the different ways of learning and students' individual differences in the teaching process, producing situations of success or failure at school. Building on studies about success and failure at school (SAWAYA, 2012; PROENÇA, 2002; CASTRO; PIOTTO, 2007) and the Historical-Cultural Theory (VYGOTSKY, 2007, 2010, 1995), we analyse teacher guidelines and formulation of student questions in six textbooks, and point out the importance of considering the heterogeneity in school classes, understanding it as a source of development (VIGOTSKI, 2010). The investigations showed that the adjustments in the educational activities made by the teacher are very important and must be taken into consideration to better assist the students in the different ways of learning, creating situations of school inclusion and success.

KEYWORDS: literacy textbooks; individual differences; development sources (Vygotsky)

\footnotetext{
${ }^{1}$ Pedagoga, Mestre em Educação pela Faculdade de Filosofia Ciências e Letras de Ribeirão Perto - USP.

${ }^{2}$ Docente do Programa de Pós-Graduação em Educação e do Departamento de Psicologia Educacional da Faculdade de Educação da UNICAMP. Pedagoga, Mestre e Doutora em Educação pela UNICAMP. Membro do Grupo de Pesquisa Pensamento e Linguagem (GPPL) - FE-UNICAMP.
} 


\section{Introdução}

No presente texto, problematizamos de que modo algumas políticas públicas educacionais que se efetivam por meio de implementação e uso de determinados livros didáticos de alfabetização podem/poderiam deflagrar formas inclusivas de intervenção pedagógica, tendo em vista as diferenças individuais, a diversidade relacionada aos modos de aprender e aos percursos de desenvolvimento.

Para tanto, retomando a discussão que desenvolvemos em outros trabalhos (SILVA, 2011, 2015), destacamos alguns aspectos do Programa Ler e Escrever, que se configura como um programa do governo estadual paulista para o ensino da leitura e escrita sistematizado em uma coleção de livros didáticos para os anos iniciais do Ensino Fundamental, e do Programa Nacional do Livro Didático (PNLD), que estabelece diretrizes que circunscrevem as orientações presentes nos manuais dos livros didáticos orientados ao professor. Por meio de análises de propostas de atividades e de orientações para o professor presentes em dois volumes do programa Ler e Escrever e em quatro livros de alfabetização aprovados pelo PNLD, explicitamos como os diferentes percursos e ritmos de aprendizado podem ser contemplados pelas propostas educativas, tendo em vista a criação de condições mais adequadas para a participação de todos os alunos nos processos educativos.

Nosso objetivo é, assim, analisar como a inclusão e o cuidado com as diferenças, em especial as diferenças relacionadas ao processo de aprendizagem dos alunos são contempladas pelos livros didáticos por nós selecionados, a fim de compreender como estas propostas podem produzir e potencializar situações de fracasso ou sucesso escolar.

\section{Diferenças e diversidade: desenvolvimento cultural, sucesso e fracasso escolar}

A questão dos diferentes ritmos e processos de aprendizado pode ser melhor compreendida a partir dos argumentos de Vigotski e de autores da perspectiva histórico-cultural. Segundo o autor (VIGOTSKI, 1995, 2010), o desenvolvimento cultural resulta da apropriação das experiências sociais e culturais que são vivenciadas de forma diferenciada por cada indivíduo, o que explicaria as diferenças individuais: "É a sociedade e não a natureza que deve figurar em primeiro lugar como fator determinante do comportamento do homem. Nisso consiste toda a ideia de desenvolvimento cultural" (VIGOTSKY, 1995, p. 89). Nesta perspectiva, portanto,

[o] desenvolvimento psíquico não é entendido como a efetivação das possibilidades biológicas predefinidas, mas está enraizado nas formas de mediação e de interação social, podendo ser compreendido enquanto processo de inserção na cultura e nas relações sociais. (NOGUEIRA, 2006, p.133)

Assim, tendo em vista o processo de desenvolvimento cultural, as condições concretas condensadas no meio social e cultural não se configuram como circunstâncias que determinam o desenvolvimento, mas, como afirma Vigotski, como fonte de desenvolvimento. 
[O] meio não pode ser analisado por nós como uma condição estática e exterior com relação ao desenvolvimento, mas deve ser compreendido como variável e dinâmico. Então o meio, a situação de alguma forma influencia a criança, norteia o seu desenvolvimento. Mas a criança e seu desenvolvimento se modificam, tornam-se outros. E não apenas a criança se modifica, modifica-se também a atitude do meio para com ela, e esse mesmo meio começa a influenciar a mesma criança de uma nova maneira. (VIGOTSKI, 2010, p.691)

A concepção do meio como fonte de desenvolvimento traz uma interessante provocação para pensarmos o modo como a escola lida com as diferenças individuais. De modo geral, desde a ampla difusão do modelo de ensino simultâneo no Brasil, no final do século XIX (ALVES, 2006), a organização do trabalho pedagógico tem estado sempre orientada pela premissa de que todos os alunos não somente realizam as tarefas escolares ao mesmo tempo, mas principalmente aprendem e se desenvolvem da mesma forma e no mesmo ritmo. Ou seja, o advento de uma nova forma de organização do trabalho educativo, ensino simultâneo, a partir de algumas soluções materiais (entre elas o uso do quadro-negro em substituição às lousas individuais, por exemplo), se pautou por uma expectativa de uniformidade com relação aos processos de aprendizado dos alunos, ao mesmo tempo em que a fortalecia. Segundo esta expectativa, qualquer diferença pode ser indicativa de desvio e/ou problema.

Por outro lado, se considerarmos as práticas educativas que organizam as relações em sala de aula e oportunizam situações de aprendizagem como fontes de desenvolvimento que medeiam o desenvolvimento cultural, temos argumentos para compreender como e porque os alunos não aprendem todos ao mesmo tempo e da mesma forma. Assim, segundo esta perspectiva,

a heterogeneidade, característica presente em qualquer grupo humano, passa a ser vista como fator imprescindível para as interações em sala de aula. Os diferentes ritmos, comportamentos, experiências, trajetórias pessoais, contextos familiares, valores e níveis de conhecimentos de cada criança (e do professor) imprimem ao cotidiano escolar a possibilidade de troca de repertórios, de visões de mundo, confrontos, ajuda mútua e consequente ampliação das capacidades individuais (REGO, 1998, p.63-64).

Os estudos acerca do fracasso escolar no Brasil também contribuem de forma relevante para a compreensão das diferenças individuais. Historicamente, a forma de compreender a diversidade entre os indivíduos ou grupos, assim como o fracasso escolar tem sido muito distinta. Desde as décadas de 1920 e 1930, surgiram teorias que, sem se indagar acerca da desigualdade social, atribuíam à criança, sua família e meio social a responsabilidade pelas dificuldades de aprendizagem, reforçando os preconceitos raciais, tais como a Teoria da Carência Cultural e a Teoria da Diferença Cultural (PATTO, 1997; SAWAYA, 2002, 2012). Desta forma,

[sem] colocar em xeque a existência de igualdade de oportunidades na ordem social vigente, as teses explicativas sobre a heterogeneidade da população encontraram sustentação em ciências como a Psicologia, cuja tendência foi inicialmente atribuir a pobreza à 
inferioridade inata e, posteriormente, como decorrência de desencontros culturais devido à escassez, à privação ou à exclusão dos benefícios da civilização moderna. (SAWAYA, 2012, p.161)

Apenas a partir do final da década de 1970 e início da década de 1980, com a elaboração dos primeiros estudos que questionavam esta posição, dentre os quais destacamos as pesquisas de Gouveia, em 1976, e de Gatti, em 1981 (conforme indicado por Sawaya, 2002), configurou-se a "necessidade da investigação da participação do próprio sistema escolar na produção do fracasso" (SAWAYA, 2002, p.200). Dentre os estudos que trilharam este caminho, Patto (1997) já destacava a necessidade de também apontar o fracasso como produto da instituição escolar despreparada para atender às diferenças dos alunos.

Neste contexto de discussão, a partir do entendimento da escola como responsável pela produção do fracasso escolar e da ruptura com a ideia das dificuldades de aprendizagem como decorrência da "incapacidade" do aluno, emerge

a concepção teórica que nos permite analisar o processo de escolarização e não os problemas de aprendizagem desloca o eixo da análise do indivíduo para a escola e o conjunto de relações institucionais históricas, psicológicas, pedagógicas que se fazem presentes e constituem o dia-a-dia escolar. (PROENÇA, 2002 p.191. Grifos do autor).

Neste sentido, diversos autores (SAWAYA, 2002, PROENÇA, 2002 destacam a importância de investigar o próprio sistema escolar na produção do fracasso, indicando que as dificuldades de aprendizagem são produzidas por diferentes mecanismos escolares, tais como a qualidade do ensino oferecido aos alunos, os materiais didáticos utilizados e o excesso de atividades burocráticas que permeiam o trabalho do professor.

O fracasso escolar e a construção de uma escola comprometida com a escolarização das classes populares são produzidos pela multiplicidade de fatores que interferem no processo de escolarização, em que professor e alunos são sujeitos sociais envolvidos no conjunto de relações e sentidos que se estabelecem no interior da escola e na relação da escola com a sua clientela e a sociedade. (SAWAYA, 2002, p.204)

Entretanto, apesar do surgimento de estudos e teorias críticas com relação às teorias do Déficit e da Diferença Cultural há mais de três décadas, a questão das diferenças de aprendizagem e do fracasso escolar ainda tem sido objeto de vários estudos que, conforme apontam Castro e Piotto, "concebem as dificuldades de aprendizagem como um problema individual" (2007, p.121). Em artigo no qual apresentam análise da literatura em psicologia entre os anos 2000 e 2004, essas autoras afirmam que dentre um total de dezesseis artigos de mestrandos e doutorandos sobre o tema "fracasso escolar", apenas três desses artigos não trataram as dificuldades de aprendizagem como caráter individual, mantendo "uma visão de dificuldade de aprendizagem focalizada no contexto da aprendizagem, retirando do âmbito individual e contextualizando a família e a escola como possuindo influências no desempenho escolar" (ibid., p.123). São poucos, portanto, os trabalhos que consideram "que a escola é o espaço em que as relações sociais e 
individuais se articulam em uma rede de relações complexas que precisam ser analisadas como tais" (PROENÇA, 2002, p.192).

Tendo em vista as contribuições da psicologia histórico-cultural e dos estudos sobre o fracasso escolar brevemente retomadas acima, gostaríamos de voltar à organização das propostas educativas diante da diversidade de ritmos e processos de aprendizagem. Considerando as noções de fonte de desenvolvimento e de produção do fracasso escolar, é possível destacar que os mecanismos escolares - tudo que faz parte das complexas relações existentes no ambiente escolar, tanto entre os sujeitos como entre eles e os variados materiais escolares - constituem condições para o desenvolvimento cultural dos alunos, potencialmente produzindo situações de sucesso e também de fracasso escolar.

Para efeitos deste texto, propomos olhar para alguns livros didáticos de alfabetização do Programa Ler e Escrever e alguns aprovados pelo Programa Nacional do Livro Didático (PNLD) - como parte integrante dos complexos mecanismos escolares, entendidos como

o conjunto de objetos envolvidos nas atividades-fim da escola. Tudo aquilo que ajuda a aprendizagem que cumpre à escola patrocinar - computadores, livros, cadernos, vídeo, canetas, mapas, lápis de cor, televisão, giz e lousa, entre outras coisas - é material escolar. (LAJOLO, 1996, p.3)

Neste universo, alguns materiais escolares são mais frequentes e dominantes que outros, visto que organizam mais diretamente o processo de ensino-aprendizagem. Entre eles, destacamos os livros didáticos, ao qual todos os alunos têm acesso e porque determinam "conteúdos e condicionam estratégias de ensino, marcando, pois, de forma decisiva, o que se ensina e como se ensina o que se ensina" (LAJOLO, 1996, p.4).

Assim, por meio da análise de enunciados de algumas atividades para o aluno e de orientações do livro didático para o professor, procuramos destacar como as propostas para a organização do trabalho pedagógico e do processo ensino-aprendizagem levam em conta a diversidade entre os alunos em sala de aula, suas diferentes experiências, ritmos e processos de aprendizado.

\section{Os (manuais dos) livros didáticos de alfabetização e as orientações para os professores}

Atualmente, as escolas públicas brasileiras são contempladas por alguns programas oficiais que preveem a distribuição gratuita de livros didáticos para todos os alunos matriculados. Dentre estes programas, temos o PNLD, de responsabilidade do Ministério da Educação, que existe desde o ano desde 1985 e que em 1996 passou a analisar as coleções didáticas a serem adotadas em todas as escolas públicas do país. As editoras inscrevem suas coleções, que passam pelo crivo da avaliação do Programa, realizada em muitas etapas. Se aprovadas, as escolas fazem a escolha das coleções a serem utilizadas por um período de três anos, quando ocorrerá uma nova avaliação. As obras escolhidas 
são compradas pelo MEC juntamente às editoras. A cada ano são avaliados os livros de um determinado ciclo escolar (Ensino Fundamental I, Ensino Fundamental II e Ensino Médio e também Educação de Jovens e Adultos) (BATISTA, 2003; SAMPAIO, 2010).

Se considerarmos as escolas públicas do estado de São Paulo, existe a possibilidade de que também recebam os materiais elaborados pela Secretaria Estadual de Educação (SEESP), quando os municípios estabelecem convênio com a secretaria estadual. E, além dos livros previstos pelos programas governamentais (PNLD e SEESP), no caso daqueles municípios que decidem pela contratação dos "sistemas de ensino" privados, as escolas da rede pública ainda recebem os livros didáticos, os programas de assessoria e treinamento para os professores elaborados pelo sistema contratado.

Em qualquer uma destas situações - PNLD, SEESP ou "sistemas de ensino" - o livro didático é sempre acompanhado por orientações para o professor sobre o desenvolvimento da proposta educacional, seja na forma de um manual de orientações para uso do livro, seja na forma de comentários inseridos no próprio livro destinado ao professor, ou até mesmo na forma das orientações dadas nas atividades de formação continuada.

Como destaca Bronckart, esses documentos se configuram como prescritivos ou prefigurativos na medida em que "definem as tarefas específicas que devem ser realizadas, que pré-atribuem essas tarefas a categorias particulares de actantes e que tematizam diversos aspectos das condições de realização das tarefas, do controle de sua eficácia" (BRONCKART, 2008, p.132). Se considerarmos que, na maior parte das situações escolares, o professor recorre ao livro didático como elemento organizador do trabalho educativo, torna-se extremamente relevante observar e analisar como as orientações dadas ao professor prefiguram determinadas formas de ação e intervenção junto aos alunos. Importante ainda dizer que as orientações dadas ao professor são marcadas por determinadas concepções acerca do desenvolvimento infantil, do ensino da leitura e da escrita, mesmo quando não claramente explicitadas ao professor que, de certa forma, passa a veicular estas concepções na medida em que realiza as prefiguradas formas de intervenção educativa.

Neste sentido, buscando analisar como as orientações do livro didático podem produzir determinadas formas de ação docente diante da diversidade dos percursos de desenvolvimento dos alunos, torna-se relevante indagar: como as orientações tematizam e compreendem as diferenças individuais? Qual é o grau de generalidade ou especificidade com que os alunos são considerados? Quais são as possíveis formas de intervenção indicadas para lidar com as diferenças individuais? Ao abordar as diferenças individuais, como e quais são os agentes indicados pelas orientações para atuar junto aos alunos (a instituição, a metodologia, os professores)? ${ }^{3}$ 
Para discutir tais questões, analisaremos as orientações de livros didáticos para o professor. Selecionamos seis livros didáticos ${ }^{4}$ de alfabetização (do $1^{\circ}$ e $3^{\circ}$ anos do Ensino Fundamental), considerando: (i) as orientações para o professor inseridas ao longo das atividades no exemplar do professor; (ii) as orientações do manual do professor, geralmente colocadas como um anexo na parte final do exemplar do professor; e (iii) os enunciados das atividades dirigidas aos alunos.

\section{Livros didáticos de alfabetização e o ollhar para as diferenças}

É corrente nos manuais dos livros didáticos para o professor o discurso acerca das diferenças entre as experiências dos alunos, os ritmos e processos de aprendizagem, salientando principalmente a importância de que o professor esteja atento a todas estas questões e busque estratégias para atendê-las. Como podemos ver nos trechos abaixo destacados, dos manuais dos primeiros volumes da coleção Porta Aberta (doravante PA):

(...) Além do objetivo geralmente indicado pelo livro, o professor, que conhece os alunos e os objetivos visados com a atividade de leitura, pode propor para a leitura a finalidade que mais se adequar aos objetivos da aula e às demandas da classe. (BRAGANÇA; CARPANEDA, 2011, p. 9).

\section{E da coleção Viraver (doravante VV):}

Investigar o conhecimento que os alunos trazem consigo para a escola deve ser o ponto de partida para o planejamento da prática escolar, especialmente com crianças de classes de alfabetização.

As diferenças de contexto socioeconômico e familiar fazem com que as crianças tenham mais ou menos oportunidades de participar de atividades sociais mediadas pela escrita. No Brasil, as disparidades sociais acirram ainda mais essas diferenças: crianças oriundas de famílias que consomem a tecnologia da informática convivem com outras em cujos ambientes domésticos é difícil encontrar lápis e papel. (MIRANDA; MICARELLO; SCHAPPER, 2012, p.15)

Em alguns momentos, o manual do professor busca lançar alguma luz ao trabalho e às experiências do docente, muito no que diz respeito aos diferentes ritmos de aprendizagem dos alunos em sala de aula, às diferenças sociais e às dificuldades que podem aparecer ao longo do processo, salientando inclusive a necessidade de que o professor extrapole o material para que consiga atender às diferentes demandas dos seus alunos. O professor parece ser colocado como parte importante do processo de ensino-aprendizagem, no qual suas experiências, seus conhecimentos são postos como de extrema importância para que os objetivos de aprendizagem de seus alunos sejam atingidos por meio também do trato com as diferenças.

\footnotetext{
${ }^{4}$ Vale destacar que os seis livros foram selecionados a partir de critérios concernentes e pertinentes às pesquisas mencionadas no presente artigo (SILVA, 2011, 2015), que acabaram por se tornar objeto de investigação também neste texto. No processo de seleção dos livros para análise, buscamos um livro de cada um dos agrupamentos indicados no Guia do PNLD 2013 e o material do Programa Ler e escrever (SEESP), material largamente utilizado nas escolas públicas paulistas.
} 
Porém, ao nos depararmos com certas atividades e orientações, o lugar de destaque do professor parece desaparecer. Repetidamente, são dadas orientações ao professor, que parece ser visto como um executor de tarefas, e não como um sujeito que de fato medeia a aprendizagem dos alunos e cujos conhecimentos são de fato requisitados.

A coleção PA é repleta de indicações, orientações, "dicas", como as que abaixo reproduzimos do livro didático do professor:

Professor, é importante realizar esta atividade primeiro com seu próprio nome. Escreva-o em uma folha de cartolina, em letra de forma. Leia-o em voz alta e destaque a primeira letra. Recorte e cole uma figura cujo nome comece com essa letra.

Em seguida, peça aos alunos que escrevam o próprio nome no espaço azul e a letra inicial no espaço amarelo. Ofereça revistas ou jornais e peça que recortem uma figura cujo nome comece com a letra do nome deles. Por fim, oriente-os a colar a figura abaixo do nome.

Se julgar conveniente, amplie a atividade, pesquisando a letra inicial do seu nome grafada de várias maneiras. (BRAGANÇA; CARPANEDA, 2011, p.12 - textos em cor contrastante no original).

Professor, mais uma vez, ressaltamos a importância de transcrever a letra da música e cantá-la várias vezes, apontando as palavras com uma régua. Ao acompanhar a sua leitura, os alunos tentarão identificar onde está escrito aquilo que eles estão ouvindo.

Sugerimos também fazer uma atividade de dramatização. Para isso, forme uma roda com os alunos, na qual um aluno ficará no centro, representando o pião entrando na roda, rodando, bambeando. (ibid., p. 107 - textos em cor contrastante no original)

Os recortes sugerem o que o professor deve fazer, como deve agir, seus atos e gestos. São orientações que se voltam à prescrição do trabalho do professor, e que não mencionam os diferentes ritmos de aprendizagem dos alunos. O mesmo ocorre com as demais coleções analisadas: as páginas de atividades estão repletas de orientações, destacadas com dizeres dirigidos ao professor, e os manuais do professor, com exceção da coleção VV, apresentam além das "dicas" ao longo das atividades, uma seção do manual para "orientações" ou "sugestões" para as atividades propostas no livro do aluno. E muitas vezes, a própria instrução das atividades ao aluno é bastante diretiva sobre o trabalho do professor, como podemos ver no seguinte enunciado de livro didático do aluno da coleção Tempo de Aprender (doravante TA):

OUÇA COM ATENÇÃO O POEMA QUE O PROFESSOR VAI LER. NO POEMA, ESTÃO FALTANDO ALGUMAS VOGAIS E TAMBÉM UMA PALAVRA NO TÍTULO. QUANDO O PROFESSOR INDICAR A PALAVRA QUE PRECISA SER COMPLETADA, CONVERSE COM OS COLEGAS E O PROFESSOR PARA DESCOBRIR QUAL É A VOGAL QUE FALTA. MAS ANTES, SEU PROFESSOR VAI LER APENAS A METADE DO TEXTO E FAZER A VOCÊ ALGUMAS PERGUNTAS. (SIQUEIRA et al, 2011, p.31 - texto em caixa alta no original)

Ao mesmo tempo em que o material didático busca passar essa imagem do professor valorizado, experiente, nos deparamos com comentários que são extremamente fechados, prescritores e, até mesmo, irrelevantes. De acordo com Machado e Bronckart (2005), nos textos prescritivos para o trabalho docente, os professores 
são postos como adjuvantes ou como instrumentos de um processo que se apresenta com um caráter inelutável ou quase mecânico, sendo seu trabalho maior posto como sendo o trabalho de aplicar os princípios propostos (MACHADO; BRONCKART, 2005, p.205).

E quando o material busca, com a organização de seu discurso, dar relevância ao trabalho docente, ao mesmo tempo ele o restringe, como podemos ver ainda no manual do livro didático para o professor da coleção PA.

Como essas regras são bastante complexas [relações grafema/fonema], o professor poderá ampliar algumas atividades presentes no volume, propondo a escrita de palavras e pequenos textos contextualizados e significativos que exijam, a cada vez mais, reflexões por parte do aluno sobre qual fonema precisa representar e qual grafema deverá empregar nessa tarefa. (BRAGANÇA; CARPANEDA, 2011, p.71).

Embora o manual aponte a possibilidade de ampliação de algumas atividades, não chega a destacar que essa ampliação é esperada e necessária para atender os diferentes ritmos e processos de aprendizado. Sob o discurso de ampliação das atividades por parte do professor, o material já traz algumas atividades nas quais deverão ocorrer tal ampliação: as de escrita de palavras ou de pequenos textos. Mais uma vez, o manual planeja para o professor, determina o que deve ser feito, cabendo a ele apenas selecionar as atividades.

E vale notar também a forma como o livro didático apresenta essa ideia da ampliação das atividades. O professor "poderá ampliar algumas atividades presentes no volume", dando mais atividades no mesmo modelo das que estão presentes no livro, alongando as que lá estão. Vemos, assim, que mesmo quando a coleção PA busca passar essa ideia de que valoriza as experiências do professor para a extrapolação do material, ele restringe sua atuação. Parece, na verdade, uma armadilha da construção do discurso do manual para que o professor continue cumprindo as tarefas como forma de efetivar os objetivos anteriormente indicados pelo livro didático.

Podemos encontrar algo semelhante também no livro da coleção Fazendo e Compreendendo (doravante $\mathrm{FC}$ ). O manual afirma que

Independentemente das opções didáticas da escola, os gêneros fazem parte de nossa realidade linguística, cultural e social. Retirá-los de sua realidade concreta, transpô-los para o universo escolar e transformá-los em objetos de estudo exige observar o desenvolvimento global dos alunos em relação às suas capacidades de linguagem. E, além disso, exige proceder a uma seleção de gêneros que mais interessam aos objetivos do projeto da escola $\mathrm{e}$ pensar numa progressão curricular e em sequências didáticas que viabilizem aos alunos o contato, o estudo e a apropriação dos gêneros.(CEREJA; MAGALHÃES, 2011, p.15)

Porém, mais uma vez, quem seleciona os gêneros que serão trabalhados e a progressão curricular e as sequências didáticas? Não é o professor. Mais uma vez, é o livro didático que predefine os gêneros e os objetivos de aprendizagem da escola. Dessa forma, o livro generaliza as realidades que imagina encontrar na sala de aula, pois nenhum livro de distribuição em larga escala, como são os livros didáticos do PNLD, seria capaz de atender às realidades das escolas, aos ritmos de aprendizagem dos alunos, às 
diversidades e diferenças, restringido o trabalho com gêneros àquilo que o livro julga relevante com base nos demais documentos do MEC, como os Parâmetros Curriculares Nacionais. São necessidades imaginadas, tradadas de modo genérico, sem considerar os conhecimentos do professor, suas experiências, o conhecimento de seu ambiente de trabalho e de seus alunos. Estes são alguns aspectos a serem considerados quando tratamos da organização do PNLD.

Vale destacar que as poucas orientações ao professor acerca dos diferentes ritmos de aprendizagem e da diversidade inerente ao ambiente escolar estão presentes no manual do professor, mas não se refletem nas atividades dos alunos. Em nenhum momento encontramos considerações acerca da possibilidade de que todos os alunos não aprendam da mesma maneira, no mesmo ritmo, e que possivelmente no final do ano letivo nem todos os alunos tenham aprendido tudo. As atividades dos livros didáticos vão sendo apresentadas como se os alunos estivessem todos aprendendo da mesma forma, em um mesmo processo de elaboração do conhecimento, não sendo levantada sequer a possibilidade de algo diferente estar ocorrendo. É como se o livro didático fosse capaz de produzir os mesmos efeitos em todos os alunos, uma receita que se bem seguida pelo professor terá garantia de êxito. É o que Machado e Bronckart (2005) denominam de "contrato de felicidade", que escamoteia os possíveis problemas e desencontros.

No manual do professor do Programa Ler e Escrever, denominado de Guia de Planejamento e Orientações Didáticas do Professor Alfabetizador para a $2^{\mathrm{a}}$ série $/ 3^{\mathrm{o}}$ ano ${ }^{5}$, que se apresenta em dois volumes, um para cada semestre, os diferentes ritmos de aprendizado chegam a ser indicados em uma nota de rodapé de uma tabela com uma sugestão de organização da rotina semana de sala de aula: “*Apenas para os alunos que já sabem ler e escrever convencionalmente" e "**Para os alunos que ainda não sabem ler nem escrever" (SÃO PAULO, 2010a, p. 41).

Essas instruções, legenda da tabela de rotina semanal, indicam as atividades que deverão ser trabalhadas com os alunos ainda não alfabetizados (aquelas que ajudam o aluno a refletir sobre o sistema de escrita), e aquelas que deverão ser direcionadas aos alunos considerados alfabetizados (ortografia e separação de sílabas). Embora uma tabela semelhante, com as atividades semanais a serem propostas conforme o dia da semana, também seja apresentada no segundo volume do guia, esta legenda com ressalvas só aparece no primeiro volume. Isto seria uma indicação de que o guia pressupõe que a partir do $2^{\circ}$ semestre letivo todos os alunos já estarão escrevendo de forma convencional? E como o aluno que ainda está em processo de apropriação da escrita poderá participar das atividades?

Com relação à continuidade da reflexão do sistema de escrita para os alunos ainda não alfabetizados, o material dá indicação de que os professores ampliem seu repertório buscando atividades no volume I do Guia da $2^{\mathrm{a}}$ série $/ 3^{\circ}$ ano e nos Guias do $2^{\circ}$ ano. Sugere, portanto, que o professor busque na série anterior formas e atividades para o aluno que ainda não

Todo o material - livros do aluno e guias para o professor - do programa Ler e Escrever está disponível em: $<$ http://lereescrever.fde.sp.gov.br/SysPublic/InternaMaterial.aspx?alkfjlklkjaslkA=301\&manudjsns=2\&tpMat=0\&FiltroDeNoticias=3>. 
lê e não escreve, apesar de eles estarem em outra faixa etária, vivendo outras experiências. Além disso, não se considera que, se o aluno fez seu $2^{\circ}$ ano na escola pública estadual, ele já teria tido contato com essas mesmas atividades. O guia do Programa Ler e Escrever ainda sugere uma substituição de atividades: os alunos que sabem ler e escrever fazem atividades de pontuação e ortografia, e os que não sabem, fazem atividades de alfabetização.

Assim, nos parece que a proposta é sustentada pela noção de que o processo de aprendizagem deve passar necessariamente pelo mesmo percurso, como se houvesse uma única forma de aprender e ensinar, cabendo ao aluno se adequar a este modelo. $\mathrm{O}$ guia não chega a suspeitar que o aluno não aprenda devido à inadequação das atividades e do percurso de ensino escolhido. Isto pode ser indicativo da ideia (questionável) de que o aprendizado da escrita se dá de forma linear, dos aspectos mais simples para os mais complexos, impedindo à criança o acesso total às atividades de escrita desenvolvidas nas aulas regulares. Também não considera que na mesma atividade - por exemplo, rever coletivamente a pontuação de um texto - os alunos podem apreender e desenvolver diferentes aspectos do funcionamento da linguagem escrita, a depender do momento de elaboração da escrita em que cada um deles esteja. Desta forma, a substituição de uma atividade (pretensamente) mais complexa por uma mais simples só reitera a diferença entre os alunos: quando os alunos ainda não alfabetizados farão as atividades de pontuação e ortografia? O que os demais alunos estarão aprendendo e eles não? Será que o fato de ainda não saberem ler e escrever pode ser impeditivo de participarem e compreenderem outros aspectos do funcionamento da escrita?

Entendemos que, ao não levar em conta esta diferença de aprendizagem entre os alunos e sua diversidade, o Programa acaba por acentuar as diferenças, contribuindo mais para a produção do fracasso do que para a inclusão de todos os alunos no processo de alfabetização. As diferenças são apenas destacadas, sem que o professor tenha orientações ou alternativas para lidar com os diferentes percursos e momentos de aprendizagem dos alunos.

\section{Inclusão escolar: Por que contemplar os diferentes percursos de aprendizagem?}

Em nossas análises procuramos destacar como os livros de alfabetização selecionados preveem um percurso de ensino da leitura e escrita para um aluno idealizado. No caso das coleções aprovadas no PNLD, apesar do manual do professor mencionar a possibilidade de que nem todos os alunos aprendam no ritmo "esperado", este fato é praticamente apagado quando analisamos as atividades dirigidas aos alunos, uma vez que quase não aparecem sugestões de percursos alternativos. Com relação ao Programa Ler e Escrever, o guia dá orientações claras sobre como o docente deve proceder diante do aluno que não atendeu às expectativas de aprendizagem planejadas, prevendo que o aluno refaça o mesmo percurso, situação que, a nosso ver, não promove a inclusão, mas sim provoca uma diferença ainda maior no processo de aprendizado, uma vez que a proposta é a 
da substituição das atividades complexas por atividades mais simples. Questionamo-nos anteriormente sobre a necessidade de olharmos o modo como as orientações tematizam as diferenças individuais. Vemos assim que, apesar de menções à questão dos aspectos individuais do desenvolvimento, nos guias analisados ainda permanece a expectativa de alunos ideais, reforçando as diferenças que podem culminar em situações de fracasso.

Como Machado e Bronckart (2005) destacam, é comum que as prescrições imaginem um aluno ideal e trabalhem para ele, esquecendo que os alunos elaboram seus conhecimentos mediados pelas relações escolares, trazem experiências e conhecimentos que são distintos, se apropriam de modos diferentes dos objetos de conhecimento, aprendem em ritmos diferentes. Também esquecem que o professor, como autor de sua prática profissional, recria os instrumentos de trabalho, transforma as situações de ensino conforme observa as diferentes formas de participação dos alunos nas atividades propostas.

Vemos, portanto, que os alunos que seriam beneficiários finais das prescrições (MACHADO; BRONCKART, 2005) dos guias e manuais dos livros didáticos podem ser negligenciados pelas propostas com tendências homogeneizantes, que desconhecem os diferentes percursos de aprendizagem e, acima de tudo, não oferecem opções de atividades nas quais todos os alunos possam participar independentemente do nível de elaboração da linguagem escrita em que cada um se encontra.

Se, nas últimas décadas, uma das conquistas das escolas públicas brasileiras foi a distribuição gratuita de livros didáticos para todos os alunos, agora é fundamental pensar de que forma os livros didáticos podem ser utilizados pelos professores de forma autoral, reconhecendo que os ajustes, modificações e recriações das propostas educativas para acolher os alunos em seus mais diversos percursos definem a profissionalidade docente. Deste modo, considerando as especificidades e diferenças nos ritmos de aprendizagem dos alunos, as propostas de intervenção poderiam ser mais condizentes com as diferentes realidades escolares do que as propostas indicadas pelos livros didáticos, como as recomendações de substituição de atividades, conforme apresentamos anteriormente.

Em nome do mito da homogeneidade das salas de aula, a riqueza e fecundidade da heterogeneidade dos grupos escolares são desconsideradas. Entendemos que as formas mais inclusivas de educação são aquelas que lidam com as diferenças individuais em meio à heterogeneidade de uma classe escolar, compreendendo as situações de ensino escolar como fonte de desenvolvimento (VIGOTSKI, 2010).

E é somente por meio da (atu)ação docente que os diferentes ritmos e percursos de aprendizagem podem ser coletivamente agenciados, produzindo situações de sucesso e inclusão escolar.

\section{Referências Bibliográficas}

ALVES, G. L. A produção da escola pública contemporânea. 4.ed. Campinas, SP: Autores Associados, 2006. 
BATISTA, A. A. G. A avaliação dos livros didáticos: para entender o Programa Nacional do Livro Didático (PNLD). In: ROJO, R.; BATISTA, A.A.G. (orgs). Livro didático de Língua Portuguesa, letramento e cultura escrita. Campinas: Mercado das Letras, 2003.

BRONCKART, J.-P. O agir nos discursos: das concepções teóricas às concepções dos trabalhadores. Trad.: A.R. Machado; M.de L.M. Matêncio. Campinas, SP: Mercado de Letras, 2008.

CASTRO, L. F. R. F.; PIOTTO, D. C. Dificuldades de aprendizagem ou de ensino? Uma breve revisão da literatura em Psicologia. Aprender - Caderno de Filosofia e Psicologia da Educação, Vitória da Conquista, ano V, n.9, p. 101-126, 2007.

LAJOLO, M. Livro didático: um (quase) manual do usuário. Em Aberto, Brasília, ano 16, n. 69, pp. 3-9, jan./mar. 1996.

MACHADO, A. R.; BRONCKART, J.-P. De que modo os textos oficiais prescrevem o trabalho do professor? Análise comparativa de documentos brasileiros e genebrinos. DELTA, v.21, n.2, p.183-214, 2005.

NOGUEIRA, A. L. H. Sobre condições de vida e educação: infância e desenvolvimento humano. Horizontes, v. 24, n. 2, p.129-138, jul./dez. 2006.

PATTO, M. H. S. A produção do fracasso escolar: histórias de submissão e rebeldia. São Paulo: T.A. Queiroz, 1997.

PROENÇA, M. Problemas de aprendizagem ou problemas de escolarização? Repensando o cotidiano escolar à luz da perspectiva histórico-crítica em Psicologia. In: OLIVEIRA, M. K; REGO, T. C.; SOUZA, D. T. R. (Orgs.). Psicologia, educação e as temáticas da vida contemporânea. São Paulo: Moderna, 2002. p.177-195.

REGO, T. C. R. Educação, cultura e desenvolvimento: o que pensam os professores sobre as diferenças individuais. In: AQUINO, J. G. (Org). Diferenças e preconceitos na escola: alternativas teóricas e práticas. São Paulo: Summus, 1998.

SAWAYA, S. M. A psicologia e o Programa "Ler e Escrever": a formação de professores na escola. Educação em Revista. v. 28, n. 1, p. 157-180, mar./2012.

SAWAYA, S. M. Novas perspectivas sobre o sucesso e o fracasso escolar. In: OLIVEIRA, M. K; REGO, T. C.; SOUZA, D. T. R. (orgs.). Psicologia, educação e as temáticas da vida contemporânea. São Paulo: Moderna, 2002. p. 197-213.

SILVA, M. A. "Sabedoria para tentar cumprir, mas não passar por cima": as relações entre prescrições oficiais, trabalho docente e aprendizado na sala de reforço. 2011. Monografia (Graduação em Pedagogia) - Faculdade de Filosofia, Ciências e Letras, Universidade de São Paulo, Ribeirão Preto. 
SILVA, M. A. Pela mediação da aprendizagem em sala de aula: as orientações aos professores nos livros didáticos do $1^{\circ}$ ano do Ensino Fundamental. 2015. 131f. (Mestrado em Educação) - Faculdade de Filosofia, Ciências e Letras, Universidade de São Paulo, Ribeirão Preto.

VIGOTSKI, L.S. A formação social da mente. Trad.: J.C. Neto; L.S.M. Barreto, S.C. Afeche. 7.ed. São Paulo: Martins Fontes, 2007.

VIGOTSKI, L.S. Quarta aula: a questão do meio na pedologia. Trad.: M.P. Vinha. Psicologia USP, São Paulo, v. 21, n.4, p.681-701, 2010.

VIGOTSKI, L.S. Obras escogidas. Trad.: L. Kuper. Ver. e adap.: N.J.V. Vargas; I. Filanova. Vol. III (Problemas del desarrollo de la psique). Madrid: Visor, 1995.

\section{Livros didáticos analisados}

BRAGANÇA, A.; CARPANEDA, I. Porta Aberta: letramento e alfabetização, $\mathbf{1}^{\mathbf{0}}$ ano. São Paulo: FTD, 2011.

CEReJA, W. R.; MAGAlHÃeS, T. C. Coleção Fazendo e Compreendendo Português, $\mathbf{1}^{\mathbf{0}}$ ano. São Paulo: Saraiva, 2011.

MIRANDA, C.; MICARELLO, H.; SCHAPPER, I. Viraver: Letramento e Alfabetização, $1^{\circ}$ ano. São Paulo: Scipione, 2011.

SÃO PAULO, Secretaria da Educação. Ler e escrever: guia de planejamento e orientações didáticas; professor $-2^{\mathrm{a}}$ série / Secretaria da Educação, Fundação para o Desenvolvimento da Educação. 3. ed. São Paulo: FDE, 2010a. v. 1. Disponível em: $<$ http://lereescrever.fde.sp.gov.br/SysPublic/InternaMaterial.aspx?alkfjlklkjas-

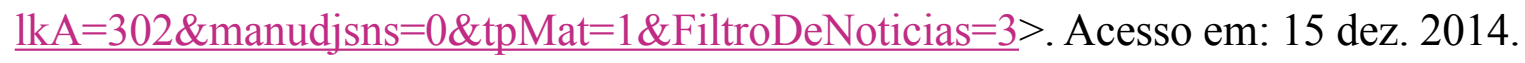

SÃO PAULO, Secretaria da Educação. Ler e escrever: guia de planejamento e orientações didáticas; professor $-\mathbf{2}^{\mathrm{a}}$ série / Secretaria da Educação, Fundação para o Desenvolvimento da Educação. 3. ed. São Paulo: FDE, 2010b. v. 2. Disponível em $<\underline{\text { http:// }}$ lereescrever.fde.sp.gov.br/SysPublic/InternaMaterial.aspx?alkfjlklkjaslkA=302\&manudjsns $=0 \&$ tpMat $=1 \&$ FiltroDeNoticias $=3>$. Acesso em: 15 dez. 2014.

SIQUEIRA, C. C.; SILVA, D. G.; SILVA, E. O.; ABROMOVICH, M. C. Letramento e Alfabetização - Coleção Tempo de Aprender, $\mathbf{1}^{\circ}$ ano. 2. ed. São Paulo: IBEP, 2011.

Recebido em: 19/12/2014

Aprovado em: 30/09/2015 